\title{
Aulas Invertidas e Práticas Lúdicas no Ensino de Redes de Computadores
}

\author{
Tarik Ponciano \\ Universidade Federal do Ceará \\ Fortaleza, Ceará, Brasil \\ tarikponciano@alu.ufc.br
}

\author{
Windson Viana \\ Universidade Federal do Ceará \\ Fortaleza, Ceará, Brasil \\ windson@virtual.ufc.br
}

\section{RESUMO}

A disciplina de Redes de Computadores é um desafio tanto para os professores, quanto para os alunos devido à sua natureza demasiadamente teórica. Para subverter essa situação, a adoção de metodologias que aumentem a motivação e o envolvimento dos alunos e os tornem protagonistas de sua aprendizagem emergem como possíveis soluções. Nesse contexto, a Aprendizagem Baseada em Jogos, do inglês Game Based Learning e Aulas Invertidas, do inglês Flipped Classroom, se apresentam como metodologias de ensino promissoras. $\mathrm{O}$ artigo descreve um conjunto de práticas criados e evoluídos durante os últimos dez anos no curso de graduação Sistemas e Mídias Digitais (compreendendo quatorze edições) da Universidade Federal do Ceará. Ao fim de cada semestre os alunos são convidados a responder um questionário avaliativo compartilhando suas experiências sobre a disciplina e os impactos das atividades e metodologias aplicadas, guiando mudanças e melhorias para as próximas versões da disciplina. Em 2020, durante o período de isolamento social causado pela pandemia global do novo coronavírus, onde uma abordagem de ensino remota precisou ser adotada, foi realizada uma avaliação antes da conclusão disciplina, para identificar possíveis problemas de adaptação do modelo. Houve grande contraste entre as avaliações do ensino em contexto presencial e remoto, o primeiro sendo avaliado, majoritariamente, de forma positiva, enquanto no contexto remoto houve maior incidência de opiniões negativas, evidenciando potenciais dificuldades de adaptação do modelo.

\section{PALAVRAS-CHAVE}

Redes de Computadores, Sala de Aula Invertida, Aprendizagem Baseada em Jogos

\section{INTRODUÇÃO}

A disciplina de Redes de Computadores faz parte do grupo de disciplinas dos cursos da área de tecnologia (e.g., Ciência da Computação, Sistemas de Informação, Sistemas e Mídias Digitais e Engenharia da Computação) cuja maioria dos alunos tem uma grande dificuldade em compreender os conceitos teóricos apresentados em sala de aula e cuja extensão do conteúdo pode tornar a disciplina um verdadeiro

Fica permitido ao(s) autor(es) ou a terceiros a reprodução ou distribuição, em parte ou no todo, do material extraído dessa obra, de forma verbatim, adaptada ou remixada, bem como a criação ou produção a partir do conteúdo dessa obra, para fins não comerciais, desde que sejam atribuídos os devidos créditos à criação original, sob os termos da licença CC BY-NC 4.0.

EduComp'21, Abril 27-30, 2021, Jataí, Goiás, Brasil (On-line)

(C) 2021 Copyright mantido pelo(s) autor(es). Direitos de publicação licenciados à Sociedade Brasileira de Computação (SBC). martírio. Em virtude desse fato, costuma-se inserir práticas de laboratório com simuladores (e.g., Cisco Packet Tracer) e ferramentas de análise de tráfego (e.g., Wireshark) para facilitar a aprendizagem ou, em alguns casos, usa-se de laboratórios experimentais preparados exclusivamente para a disciplina.

Contudo, além do conteúdo extenso, professores encontram dificuldades com o material didático, pouca disponibilidade de equipamentos adequados para a utilização de ferramentas e optam muitas vezes pelo ensino mais teórico, exacerbando ainda mais o modelo conteudista de abordagem da disciplina. Isto ocorre em grande parte devido à velocidade em que os avanços tecnológicos acontecem e ao custo de manutenção de um laboratório experimental, por exemplo [8]. Além disso, mesmo com as práticas, ainda é difícil balancear o conteúdo teórico com essas atividades, assim como estabelecer o melhor momento de inserir tais práticas ao longo da disciplina.

Desta forma, um desafio comum que se apresenta é a necessidade de utilizar métodos e abordagens que permitam tornar o processo de ensino-aprendizagem mais efetivo [13]. Uma vez que o aprendizado é um processo que deve ser vivenciado ativamente pelo aprendiz, o conhecimento e a compreensão só podem ser de fato construídos pelo próprio estudante [6], o que deveria colocar o professor em uma posição de facilitador da aprendizagem.

Torna-se, então, evidente que um modelo de ensino tradicional, centrado em um professor transmitindo conteúdos recebidos passivamente pelos alunos, pode não favorecer o aprendizado, visto que pouco oferece aos estudantes a oportunidade de vivenciar a aplicação prática dos conceitos estudados. Nesse contexto, a Aprendizagem Baseada em Jogos, do inglês GBL-Game Based Learning e Aulas Invertidas, do inglês Flipped Classroom, se apresentam como metodologias de ensino promissoras. Na metodologia de Aulas Invertidas, por exemplo, recomenda-se que os alunos venham à aula depois de concluírem um trabalho preparatório significativo (disponível normalmente online). Ou seja, o acesso e a leitura do conteúdo a ser aprendido acontece antes da aula (contrastando com as abordagens tradicionais) e o momento em sala de aula é consagrado a atividades práticas ou de consolidação ou uso do que foi aprendido.

Em geral, essas atividades são realizadas de forma colaborativa em sala de aula (por exemplo, criação de projetos, programação de software, debates temáticos, resolução de problemas)[1]. Já a Aprendizagem baseada em Jogos é uma metodologia que procura desenvolver e utilizar jogos para impulsionar o processo de ensinoaprendizagem, buscando aumentar sua efetividade e o nível de engajamento dos estudantes. Essa metodologia encontra suas raízes na teoria construtivista de educação, e é usada em diversos níveis de educação, seja em séries escolares iniciais ou em disciplinas do ensino superior. 
Nesta pesquisa, descreve-se uma série de práticas lúdicas criadas e utilizadas ao longo de nove anos de ensino de Redes de Computadores (com 14 turmas distintas). Essas práticas foram criadas para tal disciplina com o intuito de melhorar a aceitação dos alunos e a motivação de se estudar o conteúdo desta. Nos últimos três anos, parte das aulas da disciplina também foram paulatinamente invertidas de forma a propiciar mais momentos de aprendizagem prática em sala de aula. O objetivo é intercalar melhor o conteúdo teórico com as atividades práticas desenvolvidas. Ao longo do artigo, são descritas práticas que envolvem desde jogos de caça ao tesouro com Realidade Aumentada até disputas gamificadas de programação de sockets. Além disso, são apresentadas avaliações realizadas das práticas e um feedback geral de uma turma a organização da cadeira. Também descreve-se uma avaliação realizada neste ano com a adaptação da disciplina para o contexto do ensino remoto emergencial que evidenciou maiores dificuldades dos alunos com as atividades síncronas das aulas invertidas.

Espera-se que este relato de experiência possa ajudar professores de Redes de Computadores a aperfeiçoar as práticas e aulas de sua disciplina assim como instigar pesquisadores de Educação em Computação a estudar os impactos do uso de aulas invertidas e GBL neste tipo de disciplina.

O restante deste artigo está organizado da seguinte maneira: a Seção 2 apresenta as metodologias de ensino desenvolvidas na disciplina de Redes de Computadores e contextualiza o Modelo de Aulas Invertidas. A Seção 3 trata das Práticas Lúdicas aplicadas na disciplina, desenvolvidas com base nas metodologias supracitadas e uma breve descrição das instruções e funcionamento das atividades. Na Seção 4 são expostas as avaliações do modelo e da disciplina realizadas através de questionários respondidos pelos alunos. Por fim, a Seção 5 apresenta as considerações finais deste artigo.

\section{METODOLOGIA DE ENSINO}

Em nosso contexto de atuação e pesquisa, a disciplina de Redes de Computadores integraliza um total de 64 horas presenciais ao longo de um semestre letivo. Os professores dispõem de um laboratório com computadores durante todas aulas. A grade curricular da matéria é composta por aulas presenciais, na qual o Professor aborda o conteúdo com o auxílio de materiais didáticos, aulas clássicas, aplicação de Aulas Invertidas e também atividades práticas. Para estimular o engajamento dos alunos, algumas destas atividades são jogos ou possuem características lúdicas. A Figura 1 relata essas práticas e como elas são intercaladas ao longo da disciplina. No caso, usa-se a abordagem Top-Down do Kurose para ensino da pilha TCP/IP. Primeiro se inicia com uma visão geral da Internet (e.g., sua história, conceitos principais, ameaças à segurança). Em seguida, é explicada a camada de aplicação que inclui o estudo de protocolos como o HTTP, DNS, SMTP e o modelo P2P de comunicação. Em seguida, detalha-se a camada de transporte, na qual o aluno irá entender as diferenças entre TCP e UDP, assim como, realizará uma prática de programação com Sockets. Por fim, o aluno é apresentado à camada de rede, à noção de IP, endereçamento e roteamento. Nesta fase final, o aluno utiliza um farejador de pacotes para melhor entender tudo que aprendeu ao longo da disciplina (i.e., o Wireshark). Por fim, um jogo, o Net.Aura, é aplicado e engloba desafios sobre o conteúdo ministrado.

\subsection{Aprendizagem Baseada em Jogos}

Game Based Learning (GBL), em português aprendizagem baseada em jogos, é uma abordagem que faz uso de jogos para suplementar o processo de ensino-aprendizagem de forma a aumentar sua efetividade e estimular o engajamento dos alunos. Essa metodologia é influenciada pelo conceito de construtivismo da educação[3], postulado por Jean Piaget, e é a ideia de que o aprendizado é composto por uma construção de conhecimento e que é papel da educação aplicar métodos que estimulem essa construção. O GBL pode ser aplicado em praticamente todos os níveis da educação, desde os níveis escolares mais básicos, até o ensino de disciplinas de nível superior, é também defendido que a metodologia pode ser aplicada a quase todos os assuntos, e destaca-se que a união entre o material educacional e jogos pode ser uma oportunidade de ajudar os estudantes a se preparar, de forma mais efetiva e prática, para a vida em uma sociedade globalizada e tecnológica.

Essa metodologia pode ser aplicada de forma digital, através de jogos digitais ou meios digitais, ou de forma analógica e física, através de jogos de tabuleiro e de carta por exemplo, porém tem se tornado mais comum discutir GBL em seu contexto digital. De acordo com Marc Prensky, um dos proponentes do uso de aprendizagem baseada em jogos, essa mudança de paradigma para o ambiente digital se deu devido revolução tecnológica das últimas décadas[12]. É importante notar, que devido a pervasividade de meios digitais contemporâneos, as gerações mais recentes de estudantes são formadas por indivíduos nativos digitais, que desde cedo experimentaram fácil acesso e contato com aparatos tecnológicos e, desta forma, pensam e processam a informação de forma diferente de seus predecessores, os imigrantes digitais. Isso gera uma discrepância que afeta negativamente os níveis de engajamento e motivação de estudantes mais jovens com o ensino tradicional[7]. Portanto, o emprego de jogos digitais como ferramentas de ensino na sala de aula pode ser uma forma promissora de mitigar esse fenômeno, aproximando o conteúdo do que se quer ser ensinado da linguagem e estilo de aprendizagem dos nativos digitais.

As tarefas aplicadas através do GBL podem variar desde atividades muito simples, até o desenvolvimento de habilidades intricadas e resolução de problemas complexos, a análise do tipo de jogo e o tipo de atividade empregada fica por conta do professor. Para se atingir o objetivo de estimular positivamente o engajamento e ganho cognitivo dos alunos, vários fatores devem ser levados em consideração como características e necessidades dos estudantes, número de jogadores, a participação do professor e o nível de dificuldade. Para isso existem guidelines [3] sugeridas que tem como objetivo garantir a efetividade da abordagem, algumas delas são: utilizar jogos que estimulem os alunos, incentivando-os a se manter engajados na atividade; as regras e objetivos devem ser claras e plenamente compreendidas pelos participantes do jogo; os resultados devem ser destacados, oferecendo um feedback imediato aos estudantes; é importante que os participantes interajam não somente com o jogo, mas também com os outros participantes.

Através de GBL é possível explorar um grande potencial do ensino por meio do uso de jogos. Ao incorporar princípios consolidados e modelos de aprendizado, é possível criar um ambiente 


\section{Redes de Computadores}

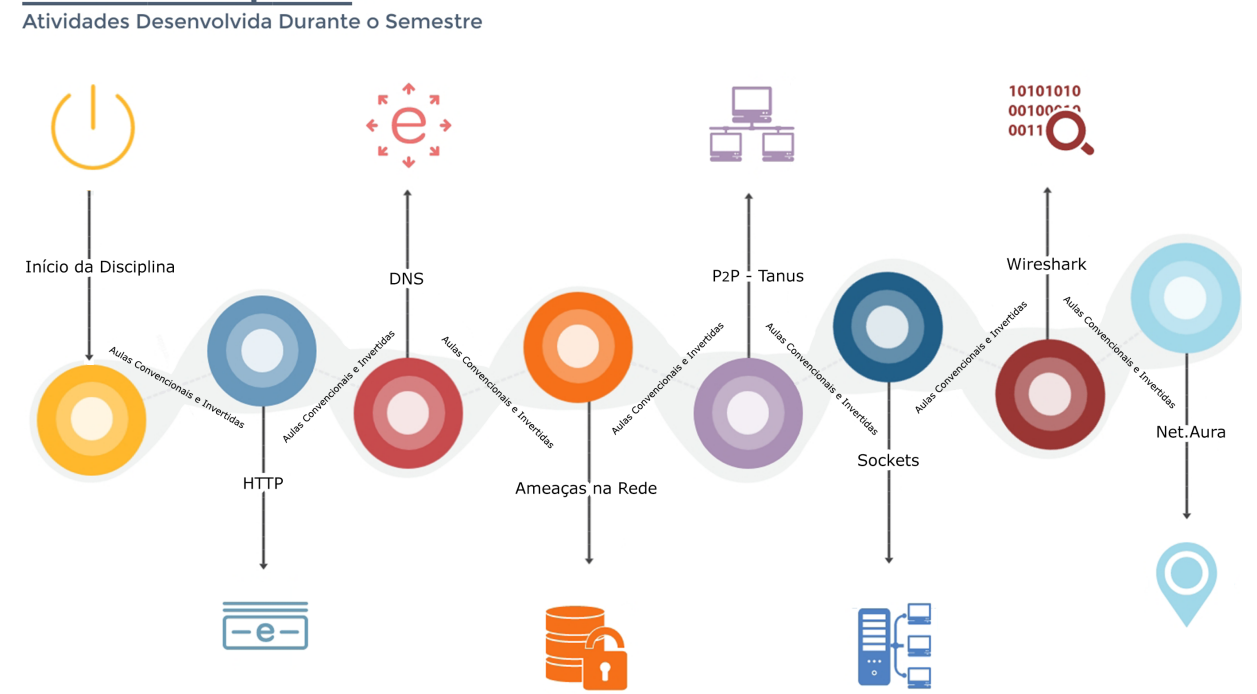

Figura 1: Timeline das atividades desenvolvidas na disciplina.

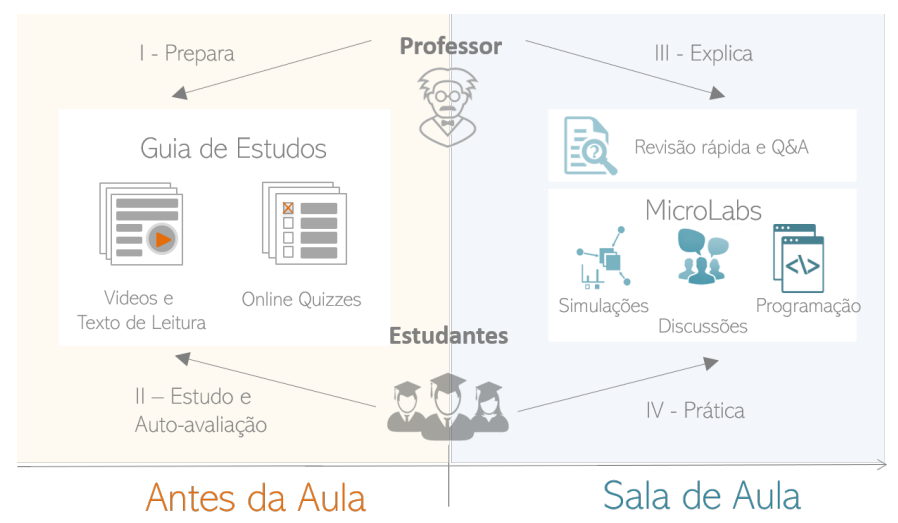

Figura 2: $\mathrm{O}$ Modelo de Aulas Invertidas adotado na nossa abordagem

educacional mais engajador e motivador que o tradicional, oferecendo experiências de aprendizagem customizadas e experiências práticas que podem consolidar em um aprendizado mais efetivo.

\subsection{Modelo de Aulas Invertidas}

A Figura 2 mostra o modelo adotado de Aulas Invertidas. Os professores da disciplina preparam um conteúdo instrucional extraclasse para ser seguido pelos alunos. Quizzes online para guiar o fluxo de estudo dos estudantes (I). Os alunos seguem as instruções e conduzem seu estudo por meio de quizzes auto-avaliativos que indicam o que ele precisa mais aprender antes de ir a aula (II). Quando a aula começa, os professores fazem uma breve recapitulação dos tópicos cobertos pelo guia de estudo e respondem às perguntas ou dúvidas feitas pelos alunos (III). Em seguida, atividades práticas são realizadas em sala de aula, e.g, alunos usam simuladores como Wireshark, discutem problemas apresentados (e.g., cenários de aplicação de uma tecnologia de enlace) ou realizam um exercício de codificação de sockets em uma linguagem de programação (IV).

O conteúdo extraclasse é estruturado como um guia de estudo. Ele segue a estrutura proposta pelo autor de [11], que integra o uso de vídeos, questionários online para auto-avaliação, quizzes, capítulos de livro, trabalhos acadêmicos, e artigos web gratuitos. Por exemplo, ao final da disciplina ocorre uma prática de revisão e aprofundamento da camada de rede TCP/IP utilizando a ferramenta de análise de pacotes Wireshark. O guia de estudo dessa aula ${ }^{1}$ usa o Google Docs e é disponibilizado para os estudantes por meio do Sistema Acadêmico Universitário. Como este conteúdo requer dos alunos conhecimento pregresso da disciplina para a realização correta da prática, o guia de estudos oferece uma ampla revisão dos conteúdos abordados durante o semestre letivo. O guia também contém questionários auto-avaliativos, que devem ser respondidos pelos alunos ao iniciar o estudo do material instrucional. O objetivo primário desses questionários é de guiar o estudo realizado por cada aluno. Após receber um feedback sobre seu desempenho e as principais fraquezas de seu aprendizado, o aluno pode priorizar os assuntos que merecem maior atenção e estudá-los. Já em sala de aula, o aluno realizará uma série de análises de tráfego para explicar como funcionam o HTTP, DNS, DHCP, PING, Traceroute assim como explicar o funcionamento diferenciado entre TCP e UDP.

As outras atividades realizadas em sala de aula usam diversas metodologias, como Aprendizagem Baseada em Problemas (PBL)[9], jogos, práticas gamificadas e também a abordagem de Microlabs. Adotada por [10], a abordagem de Microlabs defende que atividades realizadas em sala de aula devem ser curtas (5-15 minutos), e precisam ocorrer durante o tempo de aula. Os alunos podem se reunir

\footnotetext{
${ }^{1} \mathrm{O}$ guia de estudo usado na Aula Invertida de Wireshark está disponível em https: //drive.google.com/open?id=1il0uOSqDhtrA78LlfA2ncQ0gwi37nQKt
} 
em grupos, e responder à avaliações online sobre os tópicos estudados. Essas avaliações devem oferecer feedback construtivo para os alunos sobre as respostas recebidas. No caso da nossa pesquisa, os Microlabs são precedidos com explicações sobre o conteúdo antes da prática pelo professor e a resolução da prática após a realização do Microlab, tudo isso dentro de uma mesma aula. Microlabs são utilizados por exemplo na explicação dos algoritmos Go Back-N e Repetição Seletiva por meio do uso de simuladores $\mathrm{Web}^{2}$.

\section{PRÁTICAS LÚDICAS}

Como mencionado anteriormente, as atividades práticas desenvolvidas para a disciplina tiveram incorporados elementos de gamificação e ludificação. Elementos recorrentes dessas atividades são interação, narrativa, pontuação e objetivos. Como resultado há um maior engajamento e imersão por parte dos alunos, a atividade deixa de ser percebida como avaliativa, para se tornar lúdica com uma conotação educativa. Ao longo do semestre são realizadas diversas dessas intervenções. Todas focadas em algum conteúdo relevante da ementa com exceção da atividade final, que engloba os conteúdos lecionados durante o semestre na forma de um jogo em Realidade Aumentada (i.e., a prática Net.Aura). A seguir, são listadas algumas destas práticas.

\subsection{Ameaças na Rede}

Nesta etapa, os alunos, após algumas aulas invertidas e convencionais, aprendem sobre diversas vulnerabilidades e softwares maliciosos presentes na Internet. Como material preparatório para a aula é disponibilizado um roteiro de estudo que contém encartes, vídeos e um questionário auto-avaliativo. Os estudantes são incumbidos de se dividir em grupos e escrever um artigo sobre dois tipos de ameaças diferentes após a leitura do guia de estudo. A atividade prática é um desafio em sala de aula, no qual os alunos, orientados por Slides apresentados pelo professor contendo dicas e fatos acerca das Ameaças estudada, devem tentar descobrir qual vulnerabilidade ou software malicioso está sendo representado. Esses fatos são constituídos por peculiaridades da ameaça e até mesmo algumas referências da cultura pop.

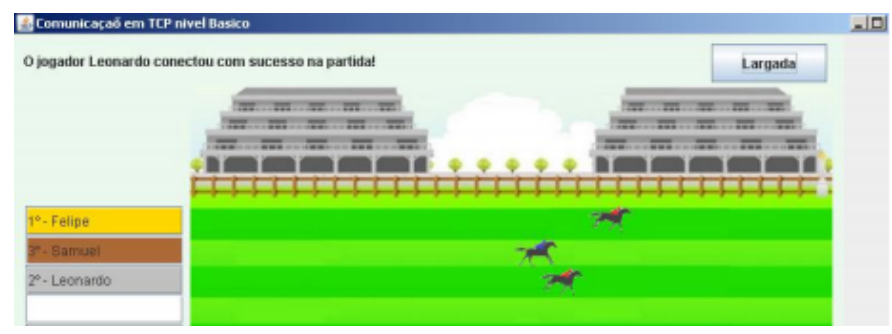

Figura 3: Os estudantes são representados por jockeys em uma corrida de cavalos.

\subsection{Sockets}

Os alunos devem aprender como funciona a comunicação entre duas aplicações distribuídas usando sockets. Ou seja, ser capaz de

\footnotetext{
${ }^{2}$ http://www.ccs-labs.org/teaching/rn/animations/gbn_sr/
}

compreender a comunicação entre duas "portas de conexão"de uma aplicação servidora e de uma aplicação cliente. Nas primeiras turmas da disciplina, os alunos tinham duas aulas teóricas sobre Sockets e na aula seguinte realizavam uma aula prática com a programação de clientes de um jogo de corrida. Essa atividade, foi replanejada em 2016 [4], e atualmente consiste em um servidor na forma de uma corrida de cavalos. Os alunos, por meio da manipulação de códigos Java de uma aplicação cliente, em sala de aula, devem se conectar ao servidor e registrar seus próprios cavalos e participar de uma corrida iniciada pelo professor competindo com os colegas. A dinâmica consiste em vários níveis de interação e complexidade, no qual os alunos gradualmente adquirem mais controle sob seus cavalos e a corrida. O professor exibe rankings de cada rodada da prática e premia os alunos que ficam em primeiro em cada rodada. A Figura 3 apresenta uma captura de tela do servidor.

Em 2019, essa atividade foi remodelada mais uma vez com a inversão de uma das aulas teórica pois, nas turmas anteriores, nem todos os alunos conseguiam acompanhar a atividade adequadamente devido a diferenças nos conhecimentos de programação. Após a primeira aula teórica, os alunos agora respondem a um préteste com oito questões sobre Sockets e Java (valendo 10 pontos). Em seguida, um roteiro de estudo é enviado para cada estudante reforçando os materiais que ele deve ter mais atenção (e.g., funcionamento do DataOutputStream). Antes da aula prática, os alunos devem responder a um pós-teste com a mesmas oito questões. A nota desse pós-teste é computada na nota da atividade, uma forma de aumentar o engajamento dos alunos na leitura do material de casa. Por fim, a atividade gamificada em sala de aula, a "Atividade dos Jockeys", é realizada. A Figura 6 mostra um exemplo de questão destas avaliações. A figura inclui também uma comparação das notas dos testes de 13 alunos da turma de 2019. Usando um Teste T-Student Pareado, com $p<0.05$, foi possível atestar que existe uma melhora significativamente das notas, o que indica que os alunos que se engajam na leitura do roteiro chegam a aula prática melhores preparados do que saíram após a primeira aula teórica.

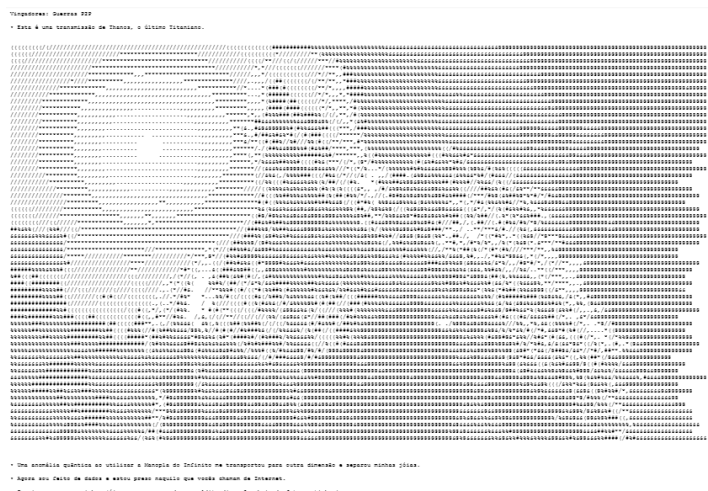

Figura 4: Arquivo de texto com instruções para a atividade inspirada na franquia cinematográfica Vingadores.

\subsection{Prática P2P - BitTorrent}

A atividade complementar para a aula de arquiteturas P2P consiste de uma prática para ilustrar e explanar o funcionamento da 

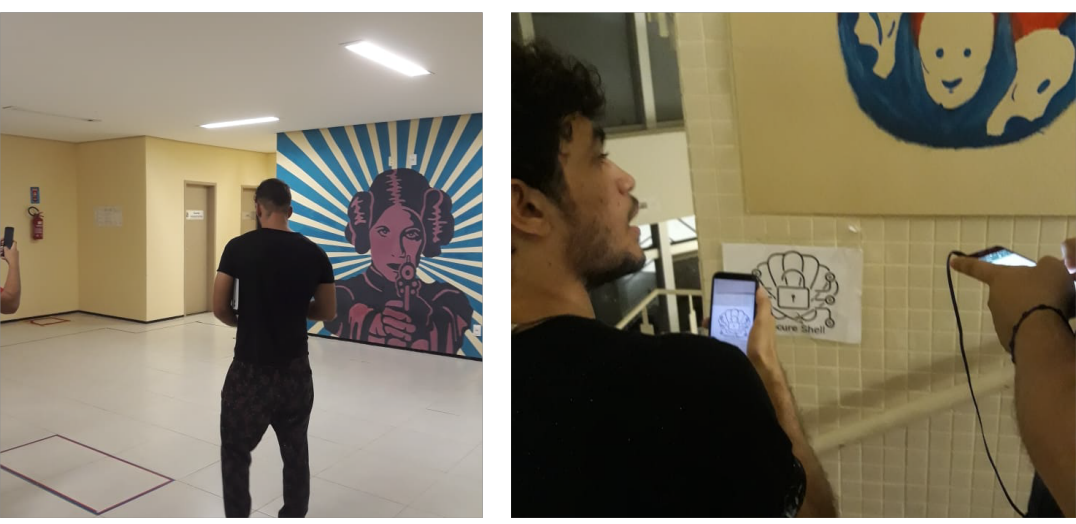

\begin{tabular}{|l|c|c|c|c|c|}
\hline & Comp I & Comp II & Comp III & Comp IV & Comp V \\
\hline $\begin{array}{l}\text { Tecnologia } \\
\text { de enlace }\end{array}$ & $?$ & $?$ & $?$ & $?$ & $?$ \\
\hline Endereço IP & $?$ & $?$ & $?$ & $?$ & $?$ \\
\hline $\begin{array}{l}\text { Camada de } \\
\text { transporte }\end{array}$ & $?$ & $?$ & $?$ & $?$ & $?$ \\
\hline $\begin{array}{l}\text { Servidor de } \\
\text { Aplicação }\end{array}$ & $?$ & $?$ & $?$ & $?$ & $?$ \\
\hline $\begin{array}{l}\text { Outros } \\
\text { Serviços }\end{array}$ & $?$ & $?$ & $?$ & $?$ & $?$ \\
\hline
\end{tabular}

01. O primeiro computador da fila está conectado sem fio pelo padrăo IEEE $802.11 \mathrm{n}$

02.0 computador ligado por cabo par trançado possui endereço IPv4 para redes locais
03.0 computador que utiliza camada de transporte TCP (Tahoe) fica ao lado do computador que possu habilitado um serviço NAT

Figura 5: Alunos scanneando marcadores implícitos(esq.) e explícitos(centro.) para solucionar o enigma(dir.) da atividade Net.Aura.

transmissão de arquivos por meio da tecnologia BitTorrent. Após a explicação do conteúdo por parte do professor, inicia-se uma exposição da criação e compartilhamento de um arquivo torrent, a conexão é manipulada de várias maneiras para mostrar aos alunos alguns conceitos estudados em aula como "rarest first" e "peer priority”. Os alunos devem então baixar nos computadores do laboratório, utilizando algum cliente bitTorrent convencional, o arquivo torrent compartilhado pelo professor. Dentro há um arquivo de texto contendo instruções para a próxima fase, a Atividade Tanus. ${ }^{3}$

A segunda fase segue a narrativa de que Tanus, personagem da franquia cinematográfica Vingadores, em um acidente com um artefato de poder, foi transportado para nossa dimensão, porém na forma de dados. Suas joias de poder foram espalhadas por diversos computadores do laboratório. Os alunos devem se dividir em equipes e de forma colaborativa com os outros alunos, por meio de compartilhamento via torrent, devem juntar as joias para montar a Manopla do Infinito e enviá-la de volta para Tanus. As equipes devem então escolher um computador que possua uma joia de poder, sendo estas 6 no total com cada equipe tendo posse inicialmente de apenas uma. Para vencer, a equipe deve fazer o download via torrent de todas as outras joias e assim montar sua própria manopla do infinito. Para que isso aconteça cada equipe deve criar um arquivo torrent contendo sua própria joia e compartilhar com os colegas, que por sua vez devem compartilhar suas próprias joias, dessa forma estabelecendo uma rede em que todos possuam acesso a todas as joias. Desta forma os alunos podem observar a propagação da informação na rede torrent e manipular diretamente a transmissão dos dados. A Figura 4 mostra um arquivo com as instruções da atividade.

\subsection{Net.Aura}

Ao fim de cada semestre o conhecimento acumulado dos alunos é posto em prova. A atividade do Net.Aura[2] acontece em formato de jogo em Realidade Virtual. Os alunos devem criar equipes pequenas, duplas ou trios, e com a ajuda da aplicação HP Reveal, antigo Aurasma, buscar imagens "gatilhos" pela unidade acadêmica

${ }^{3} \mathrm{O}$ arquivo de instruções da segunda fase da prática P2P está disponível em https: //drive.google.com/open?id=14eHyr54ophh5YH_TWiQaEouOnJLOYnGN em que estudam a fim de capturar dicas, que são melhores interpretadas usando o conhecimento adquirido ao longo da disciplina. $O$ jogo possui uma narrativa simples em que uma nave espacial terráquea teve problemas em seus 5 computadores centrais. Para solucionar o problema, os alunos devem ordenar corretamente o IP, a tecnologia de enlace, o protocolo de transporte, o servidor de aplicação e uma categoria chamada "Outros Serviços" de cada máquina. Isso acontece seguindo o formato do Enigma de Einstein, um quebra-cabeça no qual as 5 colunas relativas devem ser preenchidas corretamente utilizando uma série de parâmetros pre-estabelecidos em uma sequência correta. Para atingir esse objetivo, os alunos contam com algumas dicas iniciais ${ }^{4}$, presentes em um documento com instruções e a lista de respostas possíveis. Além disso, eles devem caçar novas dicas scanneando marcadores implícitos e marcadores explícitos, pequenas placas feitas especificamente para o Net.Aura espalhados pelo prédio. A Figura 5 ilustra essa prática.

\section{AVALIAÇÕES E FEEDBACK DOS ALUNOS}

Nesta seção, são apresentados resultados de questionários autoavaliativos e de satisfação, respondidos pelos alunos, acerca da disciplina e de atividades como P2P e Net.Aura. Acerca da avaliação do P2P, elas foram realizadas nas turma de 2019.1 e 2019.2 somando um total de 30 respostas. Já a avaliação do Net.Aura engloba três turmas, 2018.1, 2018.2, 2019.1 num total de 66 alunos e 42 respostas. Ressalta-se que o número de alunos matriculados na disciplina nos períodos indicados é superior ao número de respostas, pois nem todos participaram das aulas (e.g., trancamento) ou não responderam aos questionários de avaliação das práticas.

Em consequência do cenário de pandemia e isolamento social, e as limitações logísticas associadas, atividades como P2P, Net.Aura e Jockey não puderam ser realizadas, portanto, os resultados obtidos em 2020 são parciais e analisados separadamente.

\footnotetext{
${ }^{4} \mathrm{O}$ Documento do Net.Aura contendo todas as informações necessárias para a execução da atividade está disponível em https://drive.google.com/open?id= 1xofbv5YZragFFPnXZsxbIvPCk7i7nWdDgTbpqmtZY0s
} 
Em relação à Java Sockets, marque a opção CORRETA: *

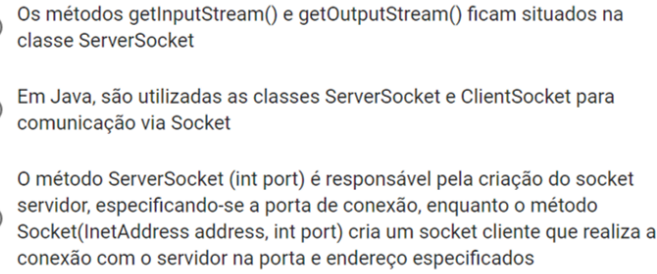

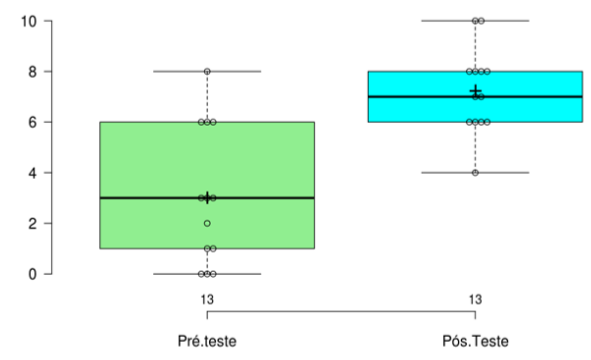

Figura 6: Exemplo de questão presente na avaliação(esq.) e efeito da prática na performance dos alunos.

\subsection{Avaliação da prática de P2P}

Aplicada em dois semestres diferentes, no total, aproximadamente 40 alunos participaram desta atividade, e um questionário respondido pelos participantes, obteve 30 respostas. O questionário era auto-avaliativo e tinha como objetivo investigar a percepção, da atividade, por parte dos alunos nos seguintes critérios: relevância do conteúdo da atividade para com o aprendizado da disciplina, relevância entre o que foi feito e o conteúdo da aula expositiva sobre o mesmo tema, diversão ao participar da atividade, contribuição da narrativa para a imersão, nível de dificuldade, compreensibilidade das instruções, nível de satisfação com a atividade prática e aula expositiva.

Os resultados foram quase unanimemente avaliados como positivos. Nos dois primeiros critérios, avaliando a relevância da atividade, todos perceberam a atividade como relevante para o aprendizado da disciplina, porém, 4 alunos $(13,3 \%)$ acharam insuficiente a relação entre o que foi feito e a aula expositiva prévia, esse problema foi corrigido para a versão de 2019.2 que não contou com respostas negativas nesse critério. Quanto a diversão ao participar da atividade 27 alunos (90\%) relataram uma experiência positiva, apenas 3 alunos (10\%) foram indiferentes quanto a atividade. A avaliação da narrativa, porém, foi um critério divisivo e 11 alunos $(36,7 \%)$ relataram indiferença ou não concordam que a narrativa possa ter contribuído significativamente para a imersão na atividade. O nível de dificuldade foi considerado fácil ou mediano alcançando uma média de 2,43, em uma escala de 1(Muito fácil) a 5(Muito difícil). Os participantes em grande maioria avaliaram as instruções como compreensíveis, apenas 1 participante relatou indiferença. Por fim as avaliações do nível de satisfação para com a atividade prática e aula expositiva podem ser vistas na Figura 7. Em uma questão aberta destinada a comentários, alunos relataram falta de familiaridade com as ferramentas utilizadas e sugeriram que parte do tempo de aplicação fosse reutilizado para aclimatização com as ferramentas.

\subsection{Avaliação do Net.Aura}

Ao fim da atividade, é pedido que os alunos respondam a um questionário avaliando a dinâmica. Ele foi criado segundo às assertivas propostas por [13] para avaliar jogos educacionais. Em um total de 42 respostas, todos consideraram a atividade relevante para o aprendizado da disciplina. Quanto à diversão, 40 afirmaram ser divertido, enquanto 2 indicaram ser indiferentes. Perguntados se recomendariam o jogo para seus colegas, 39 responderam positivamente, 40 gostariam de jogar novamente.
Avalie seu nível de satisfação geral com a atividade prática e a aula expositiva

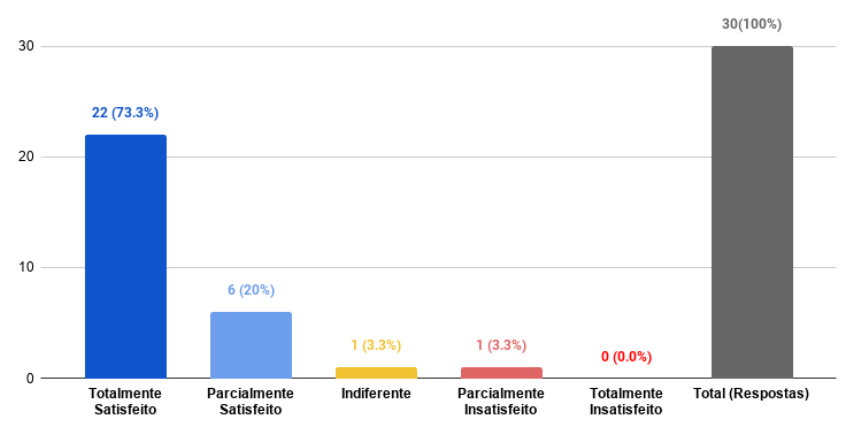

Figura 7: Avaliação de satisfação geral da atividade prática e aula expositiva sobre P2P.

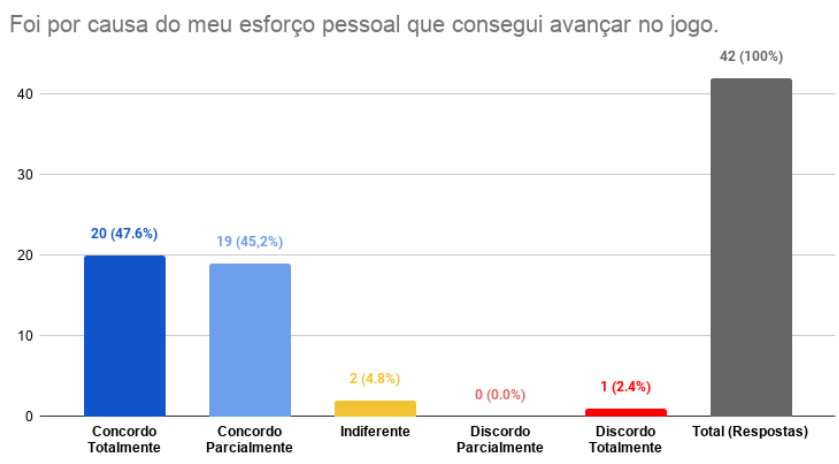

Figura 8: Contribuição do esforço pessoal para progressão na atividade Net.Aura.

Em termos de imersão, o jogo também obteve bastante sucesso. Responderam ter se sentido imersos no ambiente do jogo esquecendo o mundo real 27 dos participantes $(64,3 \%)$ e $75 \%$ sequer perceberam o tempo passar durante a atividade. No quesito interação entre os alunos, todos disseram ter se divertido jogando junto de outras pessoas e 40 responderam ter interagido diretamente com outros colegas, 41 concordaram que o jogo promove momentos de cooperação e/ou competição entre os participantes. Os participante 
se sentiram recompensados pelo seu esforço pessoal como visto nas Figura 8.

As reclamações mais frequentes, feitas por meio de questões abertas do questionário, ficaram por parte da necessidade constante de acesso à Internet para caçar as pistas e também algumas pistas em áudio que tinham a compreensibilidade debilitada devido à pronúncia do narrador digital. Na versão de 2019, alguns áudios foram melhorados em função desse feedback.

\subsection{Avaliação Geral da Disciplina}

Ao fim do semestre letivo, é pedido aos alunos de Redes de Computadores que respondessem a um questionário avaliando a disciplina. Em 2019.1, o questionário obteve 13 respostas dos 20 que concluíram a disciplina. Acerca do modelo de aulas invertidas 5 alunos $(38,5 \%)$ avaliaram os roteiros de estudo como extensos e todos avaliaram o conteúdo em vídeo dos roteiros como de boa qualidade, foi pedido também que escolhessem suas atividades favoritas $9 . \mathrm{O}$ Net.Aura foi a atividade mais escolhida com 8 votos, na sequência ficaram a prática Wireshark e a P2P Thanos com 7 votos cada uma. Já sobre quais atividades foram mais úteis para o aprendizado na disciplina ficaram empatadas as atividades de Ameaças na Rede, Net.Aura e Wireshark.

Todos os alunos participantes avaliaram as práticas em sala de aula como compatíveis com o conteúdo estudado e também que gostariam de mais disciplinas do curso de graduação incluísse aulas invertidas e práticas como as de Redes de Computadores. Todos avaliaram os vídeos usados nos roteiros como de boa qualidade, porém $5(38,5 \%)$ responderam que os roteiros de estudo eram um pouco extensos. 4 alunos $(30,7 \%)$ acharam o tempo inadequado para estudar esses roteiros. O modelo de aulas invertidas foi elogiado por alguns dos alunos em um espaço de feedback aberto, as reclamações ficaram por conta de tempo insuficiente em sala de aula pra realizar algumas das práticas.

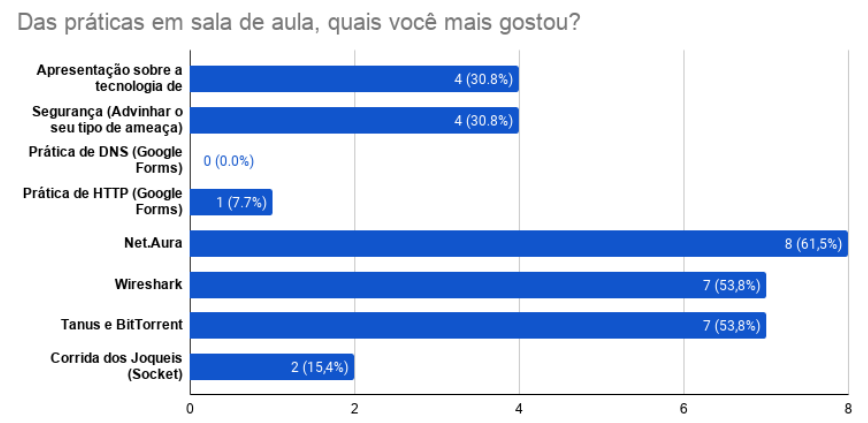

Figura 9: Lista das atividades realizadas e votos de aprovação dos alunos.

\subsection{Avaliação Parcial da Disciplina em Contexto Remoto}

Como mencionado anteriormente, o cenário atípico de isolamento social impactou fortemente a dinâmica vigente da disciplina. Para se adaptar ao contexto remoto, as aulas em sala de aula deram lugar a vídeo-conferências em um canal criado para a disciplina na plataforma de vídeos Youtube, onde as aulas ficariam gravadas para acesso assíncrono dos alunos. Essa mudança de ambientação trouxe prejuízos para a aplicação da metodologia de Microlabs, uma vez que não havia garantia da infraestrutura necessária para que os alunos realizassem as atividades.

Desta forma a disciplina precisou sofrer uma readaptação, e atividades como Net.Aura, P2P Tanus e Jockeys não puderam ser aplicadas. Foi mantida, porém, a dinâmica de sala de aula invertida, onde os alunos eram estimulados a cumprir um roteiro de estudos antes das aulas expositivas.

Para verificar o contraste entre a aplicação convencional da disciplina e seu modelo adaptado para o contexto remoto, foi feito um questionário auto-avaliativo parcial, antes do fim do semestre letivo, que contou com resposta de 16 alunos. Comparado a 2019 a quantidade de avaliações negativas dos quesitos do questionário foi substancial, indicando uma dificuldade de adaptação ao contexto remoto. A Figura 10 mostra a proporção de opiniões positivas das perguntas do questionário comparando os anos de 2019 (azul) e 2020 (vermelho). Assim como em aplicações do questionário anteriores, foi perguntado aos alunos se concordavam ou discordavam da seguinte afirmação "Os roteiros de estudo eram extensos", em uma escala de Discordo Totalmente a Concordo Totalmente, na avaliação de 2020 a proporção de alunos que acharam o roteiro extenso foi para 50\%(8 alunos) e nenhum aluno discordou totalmente da afirmação, ao contrário de outros semestres. Até mesmo a percepção da qualidade dos vídeos dos roteiros teve um prejuízo, antes considerados de boa qualidade por unanimidade, dessa vez 5 alunos avaliaram negativamente a qualidade dos vídeos. Acerca da compatibilidade entre as práticas e o conteúdo estudado, 11 alunos (68,8\%) avaliaram como compatíveis. O tempo disponível entre aulas expositivas para estudar o roteiro foi percebido como adequado por 12 participantes (75\%). Já a proporção de alunos que gostariam que o modelo fosse adotado em outras disciplinas caiu de $100 \%$ para $31,3 \%$.

Considerando a opinião menos positiva dos alunos em relação às aulas invertidas, percebe-se que a ausência da prática de forma presencial e colaborativa pode ter sido um dos fatores que influenciaram nesta percepção. Além disso, os alunos se sentem mais sobrecarregados nesse modelo de ensino remoto e precisam de mais tempo para melhor seguir os roteiros de estudos das aulas invertidas. Outro ponto é que as práticas lúdicas melhor avaliadas anteriormente não puderam ser realizadas na disciplina, o que também pode ter contribuído o aumento de opiniões negativas. Ao final, a disciplina em modelo remoto emergencial teve taxas semelhantes de aprovação ( $86 \%$ comparados a $93 \%$ em 2019.2 e $76 \%$ em 2019.1) e uma boa recepção geral dos alunos. Contudo, mais investigações precisam ser feitas em como melhor adaptar as aulas invertidas e as práticas lúdicas anteriores nesse novo contexto.

Para tentar compensar o impacto negativo evidenciado nas respostas do questionário parcial, uma das medidas adotadas foi ofertar aos alunos momentos de consultoria onde o professor se reunia com os alunos, de forma individual, para tirar dúvidas do conteúdo e de atividades. De forma preliminar, essa abordagem parece ter afetado positivamente a opinião dos alunos, como fica evidenciado em nova avaliação, dessa vez aplicada pela própria universidade na forma de um formulário semestral, chamado de avaliação institucional, que permite aos alunos avaliarem seu próprio empenho, a disciplina e os 


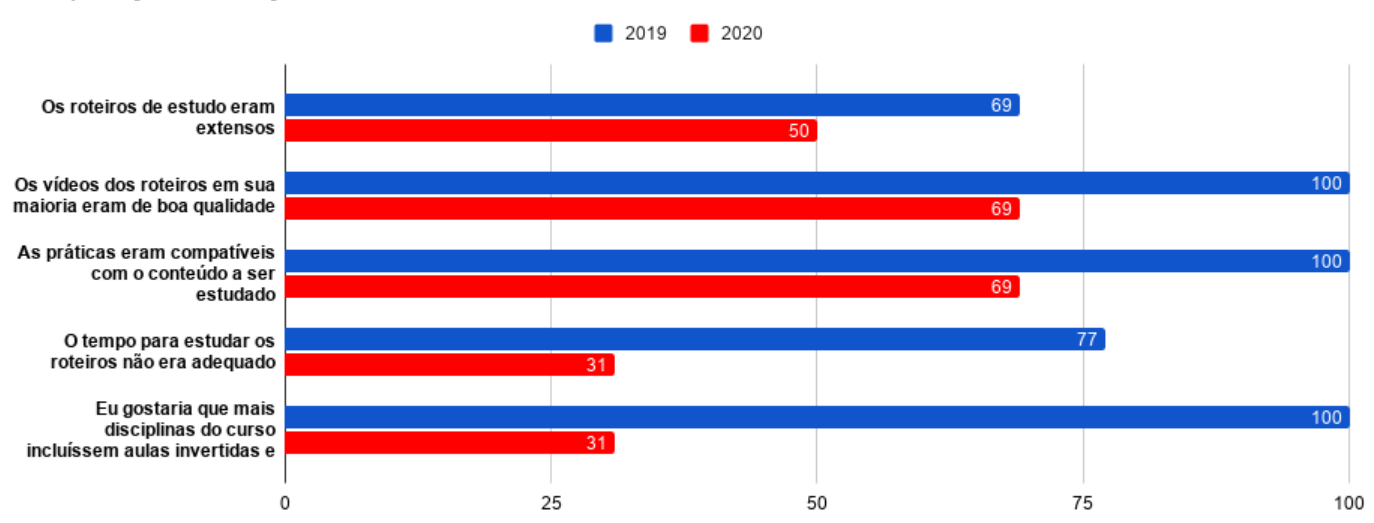

Figura 10: Comparação entre 2019 e 2020 de percentual de respostas positivas.

docentes. A avaliação do docente ${ }^{5}$ em um questionário dividido em 14 perguntas, compondo 4 dimensões avaliativas diferentes, obteve resposta de 18 alunos em uma turma de 32 alunos, os participantes da avaliação deveriam avaliar cada afirmação do questionário com uma nota de 1 a 5 , de forma a medir o desempenho do docente, ao final a nota média das avaliações foi consolidada em 4,92.

\section{CONSIDERAÇÕES FINAIS}

Neste artigo, apresentou-se brevemente o uso de aulas invertidas e práticas lúdicas no ensino de Redes de Computadores. Balancear o conteúdo teórico em sala de aula, inversão de aulas e o uso de práticas lúdicas (desde práticas gamificadas a o uso de jogos) tem sido o desafio do ensino dessa disciplina em nossa universidade, em (João dos Santos Oliveira, et al) [5] os autores propõem diversas abordagens similares a metodologia aplicada neste trabalho buscando o mesmo equilíbrio. O feedback apresentado pelos alunos indica que as aulas invertidas favorecem a aprendizagem, entretanto, exigem uma elaboração cuidadosa de sua extensão e do prazo para sua execução. Já o uso de jogos, como o Net.Aura, se mostrou de excelente aceitação nas últimas três turmas da disciplina e como mostrado nos resultados é a prática mais apreciada pelos alunos.

Como trabalhos futuros, pretende-se investigar o impacto cognitivo das abordagens com intuito de melhor compreender como elas afetam a aprendizagem dos alunos e também como adaptações dos jogos desenvolvidos para o modelo presencial possam ser realizados no ensino remoto emergencial.

O material da disciplina será disponibilizado em um repositório $\mathrm{GitHub}^{6}$, contando com todas as atividades desenvolvidas, roteiros de estudo e questionários aplicados.

\footnotetext{
${ }^{5}$ Relação das Dimensões/Questões da avaliação institucional da UFC disponível em https://cpa.ufc.br/wp-content/uploads/2017/03/avaliacao-institucional-tutorial2015.1-v2.pdf

${ }^{6}$ Repositório dos materiais apresentados nesse trabalho disponível em https://github. com/TarikPonciano/RedesDeComputadoresSMD
}

\section{AGRADECIMENTOS}

A realização desse projeto só foi possível graças ao financiamento parcial por parte do Programa de Iniciação à Docência (PID) da UFC e do Programa Institucional de Bolsas de Iniciação Científica (PIBIC) em convênio entre a UFC e o Conselho Nacional de Desenvolvimento Científico (CNPq)

\section{REFERÊNCIAS}

[1] Jonathan Bergmann and Aaron Sams. 2012. Flip your classroom: Reach every student in every class every day. International Society for Technology in Education.

[2] Nayana Carneiro, Ana Machado, Cassio Laureano, Raul Cavalcante, and Windson Viana. 2018. Net.Aura: Design e Aplicação de um Jogo de Realidade Aumentada no Ensino de Redes de Computadores. (11 2018).

[3] Heather Coffey. 2009. Digital game-based learning. (2009).

[4] Vitor Costa, Windson Viana, and Emanuel Coutinho. 2017. Um Relato sobre a Monitoria da Disciplina de Redes de Computadores no Curso de Sistemas e Mídias Digitais. Revista Sistemas e Mídias Digitais (RSMD) (04 2017).

[5] João dos Santos Oliveira e Priscila Neves Lima e Cedric de Carvalho e Amanda Silva Fonseca. 2020. Sala de aula 4.0 - Uma proposta de ensino remoto baseado em sala de aula invertida, gamification e PBL. Revista Brasileira de Informática na Educação 28, 0 (2020), 909-933. https://doi.org/10.5753/rbie.2020.28.0.909

[6] M. Ebner and A. Holzinger. 2007. Successful implementation of user-centered game based learning in higher education: An example from civil engineering. Vol. 49.3. 873-890 pages.

[7] Richard Van Eck. 2006. Digital Game-Based Learning: It's Not Just the Digital Natives Who Are Restless. Educational Review 41 (2006), 16.

[8] de Lima R. W. Chaves J. O. M. de Lima M. V. A. Ferreira, K. H. A. 2013. Inserindo um Laboratório Virtual para o Ensino de Redes de Computadores. ICBL2013 - International Conference on Interactive Computer aided Blended Learning. (2013).

[9] DA Kilroy. 2004. Problem based learning. Emergency medicine journal 21, 4 (2004), 411-413.

[10] Barry L Kurtz, James B Fenwick Jr, and Philip Meznar. 2012. Developing microlabs using Google web toolkit. In Proceedings of the 43rd ACM technical symposium on Computer Science Education. ACM, 607-612.

[11] Mary Lou Maher, Celine Latulipe, Heather Lipford, and Audrey Rorrer. 2015. Flipped Classroom Strategies for CS Education. In Proceedings of the 46th ACM Technical Symposium on Computer Science Education (Kansas City, Missouri, USA) (SIGCSE '15). ACM, New York, NY, USA, 218-223. https://doi.org/10.1145/ 2676723.2677252

[12] M. Prensky. 2001. Digital Game-Based Learning. McGraw-Hill, New York 1 (01 2001). https://doi.org/10.1145/950566.950567

[13] C. Gresse von Wangenheim R. Savi and A. Ferreti Borgatto. 2011. A model for the evaluation of educational games for teaching software engineering. 25th Brazilian Symposium on Software Engineering (SBES) (2011). 